\title{
AUGMENTED REALITY DALAM PEMBELAJARAN
}

\author{
Hendra Nelva Saputra ${ }^{1)}$ \\ ${ }^{1)}$ Universitas Muhammadiyah Kendari, Jalan K.H. Ahmad Dahlan No. 10, Kendari; \\ hendra.nelva@umkendari.ac.id
}

\begin{abstract}
Abstrak. Augmented Reality adalah salah satu teknologi yang sedang berkembang dan memiliki potensi yang baik untuk digunakan dalam proses pembelajaran. Augmented reality dapat memfasilitasi dan meningkatkan kualitas proses pembelajaran karena adanya perpaduan antara obyek virtual dengan lingkungan nyata dengan memanfaatkan penggunaan teknologi. Augmented reality dapat memvisualkan konsep abstrak untuk pemahaman dan struktur suatu model objek. Syarat utama media dapat dikatakan sebagai augmented reality yaitu mengkombinasikan objek nyata dan virtual, terintegrasi dalam objek nyata dan virtual, dan adanya interaksi secara real-time. Pemanfaatan augmented reality dalam pembelajaran telah diterapkan pada banyak mata pelajaran, seperti konsep bangun ruang dan geometri pada pembelajaran matematika, sistem pencernaan manusia dalam pembelajaran biologi, pengenalan rumah adat dalam pembelajaran IPS, dan pengenalan cara wudhu pada anak-anak PAUD/TK.
\end{abstract}

Kata Kunci. Augmented Reality, Pembelajaran

\section{The Aplication of Augmented Reality in the Teaching and Learning}

\begin{abstract}
Augmented reality is one of the developing technologies and has a good potential to apply in the teaching and learning process. Augmented reality facilitates and improves the quality of teaching and learning process because of the combination of virtual objects with real environments by taking advantage of the use of technology. Augmented reality visualizes abstract concepts for understanding and the structure of an object model. A main characteristic for a medium classified as an augmented reality is combining real and virtual objects, integrated in real and virtual objects, and a real-time interaction. The use of augmented reality in teaching and learning has already been applied to many subjects, such as the concepts of space and geometry in mathematics, the human digestive system of biology, the introduction of traditional houses in social science, and the introduction of wudhu procedure in early childhood education or kindergarten (PAUD/TK) kids.
\end{abstract}

Keywords. Augmented Reality, Teaching and Learning

\section{Pendahuluan}

Augmented reality adalah salah satu teknologi yang sedang berkembang dan memiliki potensi yang baik untuk digunakan dalam proses pembelajaran. Augmented reality dapat memvisualkan konsep abstrak untuk pemahaman dan struktur suatu model objek. Augmented reality memiliki kemampuan untuk menggabungkan objek virtual dan dunia nyata secara bersama-sama sehingga dapat menciptakan kualitas pembelajaran dan aktivitas belajar yang baik. Pernyataan ini senada dengan penjelasan Sudaryanto (2018) bahwa augmented reality dapat menghasilkan informasi tambahan kepada siswa yang ditampilkan dalam bentuk 
multimedia, sehingga membuat siswa dapat melihat simulasi yang diciptakan dan meningkatkan kualitas proses belajarnya.

Augmented reality adalah suatu media dimana informasi digital ditambahkan ke dunia fisik (Craig, 2013). Azuma dalam Ozdemir et.al (2018) menjelaskan augmented reality merupakan suatu lingkungan yang membantu pengguna untuk melihat lingkungan nyata yang disajikan oleh objek virtual sehingga objek virtual akan melekat atau menyerupai lingkungan nyata dan pengguna akan melihat keduanya dalam lingkungan yang sama. Fuhrt (2011) menyatakan augmented reality merupakan pandangan real time secara langsung maupun tak langsung lingkungan fisik dunia nyata yang telah diperluas dengan informasi virtual yang digenerasikan oleh komputer. Wang (2009) juga menjelaskan bahwa augmented reality dapat menghadirkan lingkungan kerja baru dengan menambahkan lingkungan virtual. Berdasarkan uraian tersebut, dapat dikatakan bahwa augmented reality merupakan obyek nyata secara real time ditambah dengan obyek virtual yang muncul saat menggunakan perangkat pada obyek nyata.

Pemanfaatan Augmented reality sebagai media pembelajaran telah menjadi bagian utama dalam proses pembelajaran. Ragam penelitian dalam bidang pembelajaran berkaitan dengan augmented reality telah dilakukan. Saputro \& Saputra (2015) melakukan penelitian pengembangan mengenal organ pencernaan manusia menggunakan augmented reality. Bakri, Ambarwulan, \& Muliyati (2018) melakukan penelitian pengembangan buku pembelajaran yang dilengkapi augmented reality pada pokok bahasan gelombang bunyi dan optik. Ananda, Safriadi, \& Sukamto (2015) meneliti tentang penerapan augmented reality sebagai media pembelajaran mengenal planet-planet di tata surya. Penelitian lain dalam pembelajaran matematika dilakukan oleh Dinayusadewi \& Agustika (2020) yang melakukan pengembangan aplikasi augmented reality sebagai media pembelajaran matematika dalam materi geometri sekolah dasar.

Bertitik tolak uraian di atas, augmented reality telah memberikan ruang baru media pembelajaran yang dapat digunakan dalam pembelajaran. Augmented reality dapat memfasilitasi dan meningkatkan kualitas proses pembelajaran karena adanya perpaduan antara obyek virtual dengan lingkungan nyata dengan memanfaatkan penggunaan teknologi sebagaimana hasil penelitian Mauludin, Sukamto, \& Muhardin (2017) bahwa nilai rata-rata siswa mengalami kenaikan dari 72,5 menjadi 90,5 ketika diajar menggunakan augmented reality. Augmented reality dapat memudahkan siswa dalam pembelajaran karena dapat melihat visualisasi struktur suatu model objek. Augmented reality juga dapat membantu siswa di daerah-daerah pelosok di Indonesia untuk melihat visualisasi benda, buah, dan lingkungan yang tak dapat ditemukan di lingkungan sekitarnya. Augmented reality secara spesifik dapat digunakan dalam pembelajaran matematika seperti pada materi bangun ruang dan geometri.

\section{Syarat Media Augmented Reality}

Prasetiyo, Setyosari, dan Sihkabuden (2017) memaparkan bahwa untuk dapat dikatakan sebagai augmented reality harus memenuhi tiga persyaratan yaitu mengkombinasikan objek nyata dan virtual, terintegrasi dalam objek nyata dan virtual, dan adanya interaksi secara real-time. Menyajikan objek nyata secara real-time menjadi suatu persyaratan suatu 
lingkungan dikatakan augmented reality. Hal ini dipengaruhi oleh augmentable suatu marker. Unity sebagai program pengembang augmented reality memberikan kriteria berupa bintang. Bintang-bintang ini merupakan tingkatan augmentable suatu marker. Tingkatan ini terdiri dari bintang satu sampai lima, semakin tinggi augmentable suatu marker maka semakin cepat marker akan terdeteksi. Pemilihan augmentable marker perlu diperhatikan dalam mengembangkan lingkungan augmented reality.

Ganapathy (2013) memberikan gambaran tentang hal-hal yang perlu dipahami ketika mendesain augmented reality. Hal-hal tersebut adalah (1) skenario penggunaan, (2) interaksi modalitas meliputi voice/audio, touch-based, tactile feedback, (3) bentuk perangkat meliputi ultra mobile device, MID, camera, smartphones. Ketika mendesain augmented reality perlu dipertimbangkan bagaimana interaksi manusia dengan augmented reality. Meningkatkan pengalaman pengguna dengan cara meningkatkan fungsi dari suatu teknologi yang digunakan untuk menampilkan informasi tambahan. Salah satu cara meningkatkan fungsi teknologi ialah dengan menyediakan fasilitas multi-touch. Tersedianya fasilitas multi-touch maka pengguna akan dapat memanipulasi objek 3D. Fasilitas multi-touch yang diberikan dalam objek augmented reality adalah rotasi objek, memperbesar dan memperkecil objek. Fasilitas ini akan membantu pengguna untuk memperoleh informasi yang dibutuhkan dengan lebih spesifik.

Mustaqim dan Kurniawan (2017) memaparkan bahwa pada dasarnya, prinsip kerja Augmented Reality adalah pelacakan (tracking) dan rekonstruksi (reconstruction). Pada mulanya marker dideteksi menggunakan kamera. Cara deteksi dapat melibatkan berbagai macam algoritma missal edge detection, atau algoritma image processing lainnya. Data yang diperoleh dari proses pelacakan digunakan dalam rekonstruksi sistem koordinat di dunia nyata. Disamping menambahkan obyek ke dalam lingkungan nyata, augmented reality juga dapat "menghilangkan" obyek nyata dalam bentuk virtual. Dengan menutupi obyek nyata tersebut dengan disain grafis sesuai lingkungannya, maka obyek nyata akan tersembunyi dari pengguna. Selanjutnya, mereka juga menjelaskan kelebihan dari augmented reality adalah: 1) Lebih interaktif, 2) Efektif dalam penggunaan, 3) Dapat diimplementasikan secara luas dalam berbagai media, 4) Modeling obyek yang yang sederhana, karena hanya menampilkan beberapa obyek, 5) Pembuatan yang tidak memakan terlalu banyak biaya, 6) Mudah untuk dioperasikan.

\section{Pemanfaatan Augmented Reality dalam Pembelajaran}

Pemanfaatan augmented reality dalam pembelajaran telah diterapkan pada banyak mata pelajaran. Pembelajaran matematika menjadi salah satu ruang lingkup yang tepat untuk memanfaatkan keberadaan augmented reality. Suharso (2012) melakukan penelitian model pembelajaran interaktif bangun ruang 3D berbasis augmented reality. Hasil penelitiannya menunjukkan model peraga bangun ruang 3D berbasis augmented reality ternyata mampu menciptakan suasan baru yang lebih interaktif dalam pembelajaran matematika. Penelitian serupa juga dilakukan oleh Nugroho \& Ramadhani (2015) yang berkesimpulan bahwa aplikasi pengenalan bangun ruang berbasis augmented reality bermanfaat untuk pengenalan bangun ruang siswa sekolah dasar dan membuat siswa lebih mudah dalam memahami dengan melihat bentuk bangun ruang secara 3 dimensi. Penelitian lainnya dilakukan oleh Rusnandi, Sujadi, \& Fauzyah (2015) dalam kesimpulannya menjelaskan bahwa augmented 
reality dapat digunakan sebagai media pembelajaran sebagai alat peraga pemodelan geometri bangun ruang yang ditampilkan secara visual berbentuk 3 dimensi.

Pelajaran lain yang juga sudah mulai memanfaatkan augmented reality dalam pembelajaran adalah mata pelajaran biologi. Hasil Penelitian Juannita \& Adhi (2017) menunjukkan penggunaan augmented reality dalam pembelajaran membuat siswa lebih aktif sehingga menarik minat siswa untuk mempelajari materi sistem pencernaan manusia. Mauludin, Sukamto, \& Muhardin (2017) dalam penelitiannya melakukan penerapan augmented reality sebagai media pembelajaran sistem pencernaan pada manusia dalam pembelajaran biologi. Qumillaila, Susanti, \& Zulfiani (2017) melakukan inovasi yang berbeda dengan melakukan pengembangan augmented reality versi android sebagai media pembelajaran sistem ekskresi manusia. Augmented reality juga telah merambah pada mata pelajaran lainnya. Supriono \& Rozi (2018) melakukan penelitian pemanfaatan augmented reality pada mata pelajaran kimia dengan judul pengembangan media pembelajaran bentuk molekul kimia menggunakan augmented reality berbasis android. Pembelajaran IPS di sekolah dasar juga mulai menerapkan augmented reality dalam proses belajar mengajar, sebagaimana penelitian Pramono (2013) tentang pembelajaran rumah adat Indonesia menggunakan augmented reality. Wahyudi, Sumual, \& Sumual (2016) memanfaatkan augmented reality untuk kebutuhan lainnya yaitu sebagai translator real time Bahasa Indonesia-Tombulu dan Tombulu-Indonesia. Pemanfaatan augmented reality bahkan telah digunakan dalam pembelajaran di PAUD dan TK. Dhiyatmika, Putra, \& Mandenni (2015) memanfaatkan augmented reality sebagai magic book pengenalan binatang untuk siswa TK. Setiawan, Syaripudin, \& Gerhana (2016) menerapkan augmented reality pada buku panduan wudhu untuk anak-anak.

\section{Contoh Marker dan Tampilan Augmented Reality}

Marker augmented reality dimaksudkan sebagai tempat pindai untuk dapat melihat gambar 3 dimensi yang dihasilkan menggunakan android. Contoh marker dan tampilan augmented reality dapat dilihat pada beberapa gambar berikut

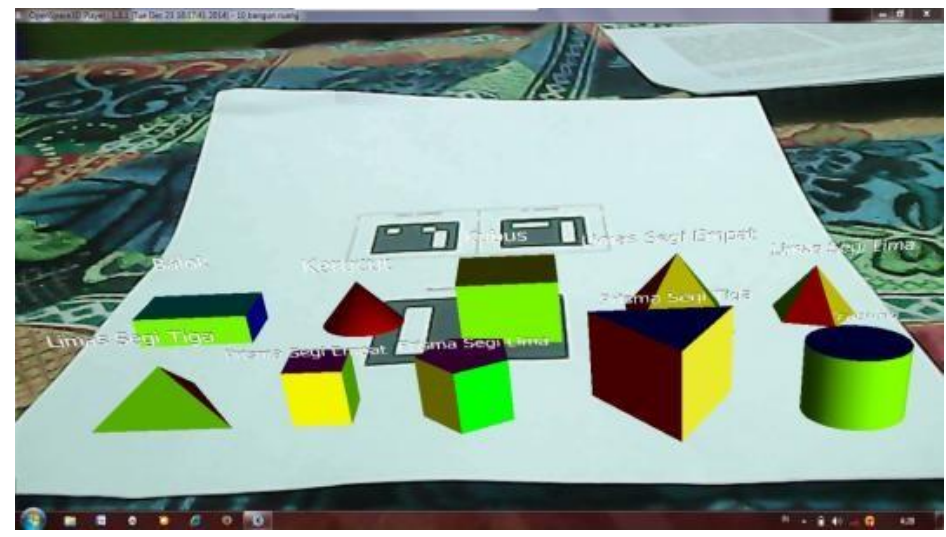

Gambar 1. Tampilan AR 10 Bangun Ruang (Sumber: Rusnandi, Sujadi, \& Fauzyah, 2015) 


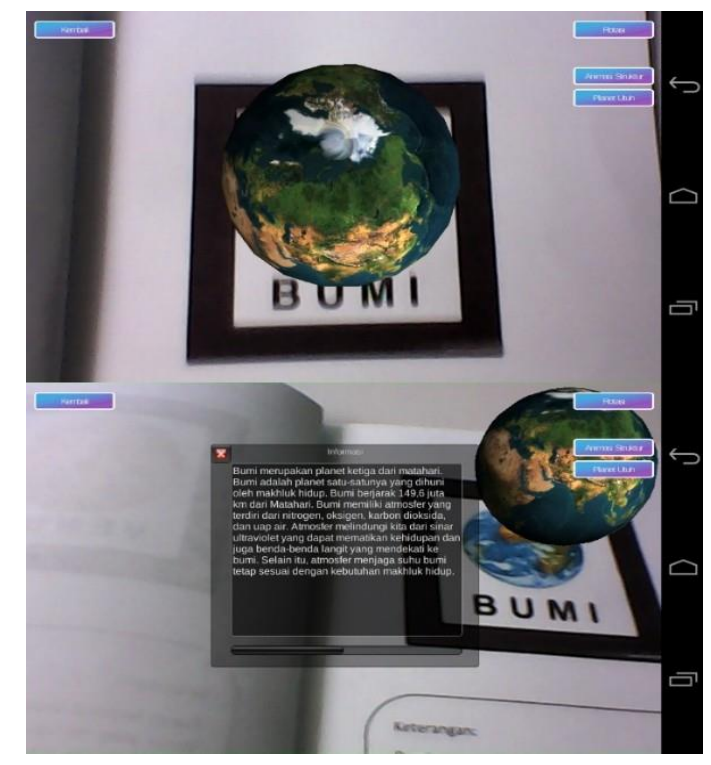

Gambar 2. Tampilan Scene Arplanet Saat Menampilkan Objek Planet dan Infonya (Sumber: Ananda, Safriadi, \& Sukamto, 2015)

\section{Simpulan dan Saran}

Simpulan yang dapat diambil berdasarkan uraian di atas adalah augmented reality merupakan obyek nyata secara real time ditambah dengan obyek virtual yang muncul saat menggunakan perangkat pada obyek nyata. Augmented reality dapat memfasilitasi dan meningkatkan kualitas proses pembelajaran karena adanya perpaduan antara obyek virtual dengan lingkungan nyata dengan memanfaatkan penggunaan teknologi. Augmented reality dapat memudahkan siswa dalam memahami konsep abstrak yang tak dapat dilihat secara kasatmata. Augmented reality telah dimanfaatkan dalam berbagai bidang terutama dalam bidang pembelajaran.

\section{Daftar Pustaka}

Ananda, T. A., Safriadi, N., \& Sukamto, A. S. 2015. Penerapan Augmented Reality Sebagai Media Pembelajaran Mengenal Planet-Planet di Tata Surya. Jurnal Sistem dan Teknologi Informasi (JUSTIN), 1(1), 1-6.

Bakri, F., Ambarwulan, D., \& Muliyati, D. 2018. Pengembangan Buku Pembelajaran yang Dilengkapi Augmented Reality Pada Pokok Bahasan Gelombang Bunyi dan Optik. Gravity: Jurnal Imliah Penelitian dan Pembelajaran Fisika, 4(2), 46-56. http://dx.doi.org/10.30870/gravity.v4i2.4032

Craig, A. B. 2013. Understanding Augmented reality Concepts and Applications. USA: Elsevier.

Dhiyatmika, I. D. G. W., Putra, I. K. G. D., \& Mandenni, N. M. I. M. 2015. Aplikasi Augmented Reality Magic Book Pengenalan Binatang Untuk Siswa TK. Lontar Komputer, 6(2), 120-127.

Dinayusadewi, N. P., \& Agustika, G. N. S. (2020). Development Of Augmented Reality Application As A Mathematic Learning Media In Elementary School Geometry Materials. Journal Of Education Technology, 4(2), 204-210. http://dx.doi.org/10.23887/jet.v4i2.25372

Fuhrt, B. 2011. Handbook of augmented reality. New York: Springer.

Ganaphaty, S. 2013. Human Factors in Augmented Reality Environments. Switzerland: Springer Juannita., \& Adhi, B. P. 2017. Pengembangan Media Pembelajaran Sistem Pencernaan Manusia Untuk Kelas 8 SMP Dengan Fitur Augmented Reality Berbasis Android (Studi Kasus: SMPN 7 
Depok). PINTER: Jurnal Pendidikan Teknik Informatika dan Komputer, 1(1), 76-81. https://doi.org/10.21009/pinter.1.1.10

Mauludin, R., Sukamto, A. S., \& Muhardi, H. 2017. Penerapan Augmented Reality Sebagai Media Pembelajaran Sistem Pencernaan Pada Manusia Dalam Mata Pelajaran Biologi. Jurnal Edukasi dan Penelitian Informatika, 3(2), 117-123. 10.26418/jp.v3i2.22676

Mustaqim, I., \& Kurniawan, N. 2017. Pengembangan Media Pembelajaran Berbasis Augmented Reality. Edukasi Elektro, 1(1), 36-48.

Nugroho, N. A., \& Ramadhani, A. 2015. Aplikasi Pengenalan Bangun Ruang Berbasis Augmented Reality Menggunakan Android. Jurnal Sains dan Teknologi, 1(1), 20-24.

Ozdemir, M., Sahin, C., Arcagok, S., \& Demir, M.K. 2018. The Effect of Augmented Reality Applications in the Learning Process: A MetaAnalysis Study. Eurasih Journal of Educational Research, $2018(74)$, 165-186. https://www.researchgate.net/deref/http\%3A\%2F\%2Fdx.doi.org\%2F10.14689\%2Fejer.2018.74. 9

Pramono, A. 2013. Media Pendukung Pembelajaran Rumah Adat Indonesia Menggunakan Augmented Reality. Jurnal Eltek, 11(1), 122-130.

Prasetiyo, T. K., Setyosari, P., \& Sihkabuden. 2017. Pengembangan Media Augmented Reality untuk Program Keahlian Teknik Gambar Bangunan di Sekolah Menengah Kejuruan. Jinotep, 4(1), 37 46. http://dx.doi.org/10.17977/um031v4i12017p037

Qumillaila., Susanti, B. H., \& Zulfiani. 2017. Pengembangan Augmented Reality Versi Android Sebagai Media Pembelajaran Sistem Ekskresi Manusia. Jurnal Cakrawala Pendidikan, 36(1), 57-69. https://doi.org/10.21831/cp.v36i1.9786

Rusnandi, E., Sujadi, H., \& Fauzyah, E. F. N. 2015. Implementasi Augmented Reality (AR) Pada Pengembangan Media Pembelajaran Pemodelan Bangun Ruang 3D Untuk Siswa Sekolah Dasar. Infotech Journal, 1(2), 24-31. http://dx.doi.org/10.31949/inf.v1i2.40

Saputro, R. E., \& Saputra, D. I. S. 2015. Pengembangan Media Pembelajaran Mengenal Organ Pencernaan Manusia Menggunakan Teknologi Augmented Reality. Jurnal Buana Informatika, 6(2), 153-162. https://doi.org/10.24002/jbi.v6i2.404

Setiawan, E., Syaripudin, U., \& Gerhana, Y. A. 2016. Implementasi Teknologi Augmented Reality Pada Buku Panduan Wudhu Berbasis Mobile Android. Jurnal Online Informatika, 1(1), 28-33. https://doi.org/10.15575/join.v1i1.8

Sudaryanto, M. A. 2018. Aplikasi Pengenalan Fauna yang Dilindungi Menggunakan Augmented Reality Berbasis Android. J-INTECH: Journal of Information and Technology, 6(2), 194-201. https://doi.org/10.32664/j-intech.v6i02.251

Suharso, A. 2012. Model Pembelajaran Interaktif Bangun Ruang 3D Berbasis Augmented Reality. Jurnal Ilmiah Solusi, 11(24), 1-11.

Supriono, N., \& Rozi, F. 2018. Pengembangan Media Pembelajaran Bentuk Molekul Kimia Menggunakan Augmented Reality Berbasis Android. JIPI (Jurnal Ilmiah Penelitian dan Pembelajaran Informatika), 3(1), 53-61. http://dx.doi.org/10.29100/jipi.v3i1.652

Wahyudi, A. K., Sumual, A., \& Sumual, J. 2016. Translator Real Time Bahasa Indonesia-Tombulu dan Tombulu-Indonesia Menggunakan Augmented Reality. Cogito Smart Journal, 2(2), 194203. http://dx.doi.org/10.31154/cogito.v2i2.29.194-203

Wang, X. 2009. Augmented Reality in Architecture and Design: Potentials and Challenges for Application. Int. J. Archit. Comput., 7(2), 309-326. 